\title{
The Health Benefits of Grapefruit Furanocoumarins'
}

\author{
Yu Wang and Laura Reuss ${ }^{2}$
}

Although not recommended for use with certain medications, grapefruits are known for their numerous health benefits. Both these effects come from, in part, natural chemicals called furanocoumarins. Although these biologically active plant compounds, or phytochemicals, are beneficial to overall health, some compounds have been shown to interact with numerous medications, causing adverse effects known as the "grapefruit juice effect." Furanocoumarins and flavanones are the major compounds responsible in these drug interactions. Several studies have reported that furanocoumarins present in grapefruit affect absorption of some medications by interfering with a certain liver and intestinal enzyme (Guo et al. 2000). However, numerous studies have shown that compounds in citrus fruits, including furanocoumarins, reduce inflammation and stop cancer cells from multiplying. Furthermore, they may also help repair damaged DNA that would otherwise contribute to the development of tumors. A variety of furanocoumarins can be found in all types of citrus, but those found in grapefruit possess several health-promoting properties that include anti-inflammatory, anti-cancer, anti-obesity, and bone-building effects (Madrigal-Bujaidar et al. 2013; Mahgoub 2002; Chudnovskiy et al. 2014).

The furanocoumarins found in grapefruit all originate from psoralen, a naturally occurring compound found in figs, celery, parsley, and all citrus fruits. The major furanocoumarins in grapefruit include bergaptol, bergapten, bergamottin, and epoxybergamottin (Figure 1). The amounts of these furanocoumarins have been identified for each of the seven grapefruit varieties, which include Rio

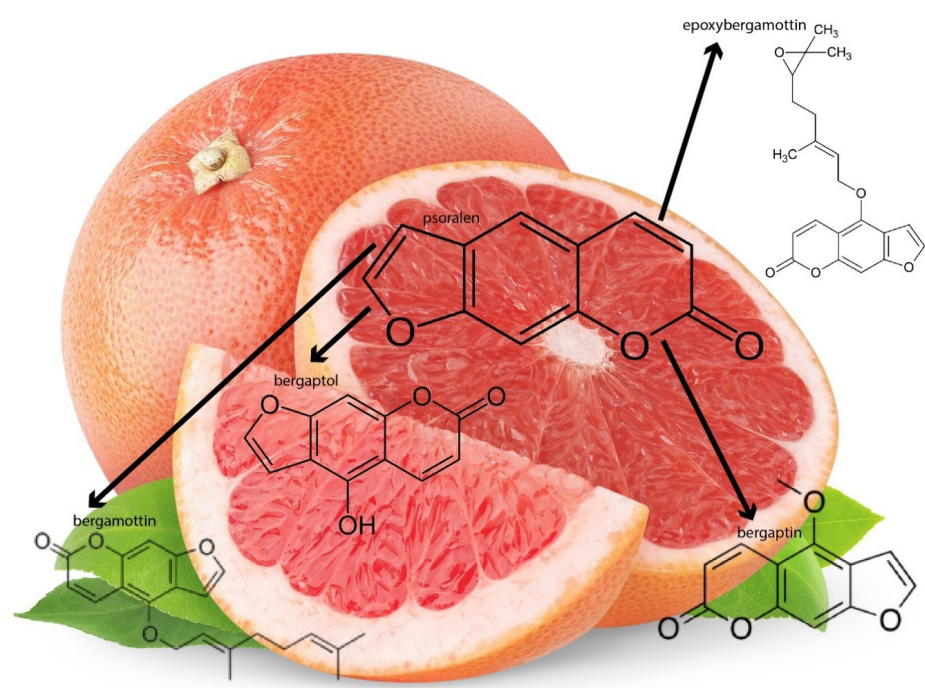

Figure 1. Furanocoumarins in grapefruit originate from psoralen and include bergaptol, bergapten, bergamottin, and epoxybergamottin.

Red, Ruby Red, Ray Red, Star Ruby, Thompson Pink, Marsh White, and Duncan (Girennavar et al. 2008).

Grapefruits have long been considered a part of a healthy diet due to being rich in vitamins, minerals, fiber, and phytochemicals, such as flavonoid and furanocoumarins. It is these phytochemicals, in particular the furanocoumarins, that demonstrate anti-inflammatory, anti-cancer, and anti-oxidative effects (Lee et al. 2016; Codoner-Franch and Valls-Belles 2010; Zou et al. 2016). For many years, studies have shown that the phytochemicals found in grapefruit, such as flavonoids and limonoids, have anti-cancer properties. Other grapefruit flavonoids, including naringin and hesperidin, are also recognized as major bioactive

1. This document is FSHN18-8, one of a series of the Food Science and Human Nutrition Department, UF/IFAS Extension. Original publication date August 2018. Visit the EDIS website at http://edis.ifas.ufl.edu.

2. Yu Wang, assistant professor; and Laura Reuss, chemist II; Department of Food Science and Human Nutrition, UF/IFAS Citrus Research and Education Center, Lake Alfred, FL 33850.

The Institute of Food and Agricultural Sciences (IFAS) is an Equal Opportunity Institution authorized to provide research, educational information and other services only to individuals and institutions that function with non-discrimination with respect to race, creed, color, religion, age, disability, sex, sexual orientation, marital status, national origin, political opinions or affiliations. For more information on obtaining other UF/IFAS Extension publications, contact your county's UF/IFAS Extension office. 
compounds responsible for grapefruit's anti-cancer effects, such as delayed development of breast cancer and leukemia (Tundis et al. 2014; So et al. 1996; Kim et al. 2013; Li et al. 2013). More specifically, bergamottin, the major grapefruit furanocoumarin derived from psoralen, has been reported to exhibit an inhibitory effect on breast cancer cell growth through the inhibition of various cell signals (Kim et al. 2014). Other grapefruit furanocoumarins, bergaptol and bergapten (both precursors of bergamottin), have also exhibited inhibitory activities against breast cancer cell growth (Panno et al. 2012). Furthermore, bergapten has also induced the death of tumor cells (De Amicis et al. 2015). In a similar manner, bergaptol was reported to significantly trigger cell death by damaging specific enzymes necessary for tumor cell division (Ge et al. 2016). Notably, several grapefruit furanocoumarins in combination can also suppress the spread of breast cancer more efficiently than if each compound was administered separately.

Multiple myeloma is a form of leukemia, a type of blood cancer, which is characterized by excess plasma cells in the bone marrow. Recent studies into the inhibitory activity of bergamottin on multiple myeloma cell growth have indicated significant reduction of these cells over time after treatment with the compound (Kim et al. 2014). Furthermore, bergamottin combined with other drugs can enhance anti-cancer effects against other types of human leukemia. The combination of such compounds as treatment significantly decreased the number of tumor cells as compared to treatment with only one of the two compounds. In a similar manner, pretreatment with bergamottin inhibited both skin cancer and stomach cancer cell growth (Yu et al. 2005). Moreover, when highly concentrated, the furanocoumarin bergamottin induces the death of neuroblastoma cells (Navarra et al. 2015). Remarkably, bergamottin not only inhibits cancer cell growth, but also suppresses metastasis by slowing human cancer cell migration (Hwang et al. 2010).

Along with anti-cancer properties, furanocoumarins have demonstrated anti-oxidative effects as well. Free radicals have long been known to cause oxidative damage to lipids, protein, and DNA due to being highly reactive with other molecules. Thus, reduction of oxidative stress through scavenging of free radicals is recognized as a promising phytochemical strategy to prevent or delay the occurrence of chronic diseases. The anti-oxidative activities of furanocoumarins, such as bergapten and bergaptol, have been shown to delay both lipid peroxidation (Hwang et al. 2010), and also exhibit free radical scavenging activities, respectively (Girennavar et al. 2007). Inflammation due to elevated oxidative stress is a biologically complex response to tissue damage, infection, or chemical influence. Chronic inflammation has long been linked to a myriad of lifethreatening, chronic diseases, such as cancer, metabolic syndrome, diabetes, and neurodegenerative disorders. Treatment using bergaptol has effectively demonstrated many anti-inflammatory effects against these diseases (Pan et al. 2010).

Another area of furanocoumarin study is osteoporosis, the bone disease characterized by loss of bone mass. Treatment with the bioactive furanocoumarin bergapten has shown significant increases in bone cell division. In addition, using bergapten to pretreat bone cell precursors for approximately one week remarkably increased the bone density in rodents and bone cell development in the marrow of humans (Meng et al. 2004).

In recent years, furanocoumarins have become a focus of investigative activities that may be biologically beneficial. However, investigations into the exact mechanisms of these furanocoumarin effects are still limited. Additional research continues not only to determine the mechanisms that benefit human health, but also to avert any negative effects caused by grapefruit juice while using certain medications. This could subsequently result in not only numerous people again enjoying the taste of grapefruit and grapefruit juice, but also reaping the furanocoumarin benefits provided by these fruits.

\section{References}

Guo, L. Q., K. Fukuda, T. Ohta, and Y. Yamazoe. 2000. “Role of furanocoumarin derivatives on grapefruit juice-mediated inhibition of human CYP3A activity." Drug Metab Disposition. 28(7): 766-771.

Madrigal-Bujaidar, E., L. M. Roaro, K. Garc1'a-Aguirre, S. Garcia-Medina, and I. Alvarez-Gonzalez. 2013. "Grapefruit juice suppresses azoxymethane-induced colon aberrant crypt formation and induces antioxidant capacity in mice." Asian Pac J Cancer Pre. 14(11): 6851-6856.

Mahgoub, A. A. 2002. "Grapefruit juice potentiates the anti-inflammatory effects of diclofenac on the carrageenaninduced rat's paw oedema." Pharmacol Res. 45(1): 1-4.

Chudnovskiy, R., A. Thompson, K. Tharp, M. Hellerstein, J. L. Napoli, and A. Stahl. 2014. "Consumption of clarified grapefruit juice ameliorates high-fat diet induced insulin resistance and weight gain in mice." PloS One. 9(10): 108408. 
Girennavar, B., G. Jayaprakasha, and B. S. Patil. 2008. "Influence of pre- and post-harvest factors and processing on the levels of furocoumarins in grapefruits (Citrus paradisi Macfed.)." Food Chem. 111(2): 387-392.

Lee, S. G., K. Kim, T. M. Vance, C. Perkins, A. Provatas, S. Wu, A. Qureshi, E. Cho, and O. K. Chun. 2016. "Development of a comprehensive analytical method for furanocoumarins in grapefruit and their metabolites in plasma and urine using UPLC-MS/MS: a preliminary study." Int J Food Sci Nutr. 67(8): 881-887.

Codoner-Franch, P. and V. Valls-Belles. 2010. "Citrus as functional foods." Curr Top Nutraceutical Res. 8: 173.

Zou, Z., W. Xi, Y. Hu, C. Nie, and Z. Zhou. 2016. "Antioxidant activity of Citrus fruits." Food Chem. 196: 885-896.

Tundis, R., M. R. Loizzo, and F. Menichini. 2014. "An overview on chemical aspects and potential health benefits of limonoids and their derivatives." Crit. Rev. Food. Sci. Nutr. 54(2): 225-250.

So, F. V., N. Guthrie, A. F. Chambers, M. Moussa, and K. K. Carroll. 1996. "Inhibition of human breast cancer cell proliferation and delay of mammary tumorigenesis by flavonoids and citrus juices." Nutr Cancer 26(2): 167-181.

Kim, J., G. K. Jayaprakasha, and B. S. Patil. 2013. “Limonoids and their antiproliferative and anti-aromatase properties in human breast cancer cells." Food Funct. 4(2): 258-265.

Li, H., B. Yang, J. Huang, T. Xiang, X. Yin, J. Wan, F. Luo, L. Zhang, H. Li, and G. Ren. 2013. "Naringin inhibits growth potential of human triple-negative breast cancer cells by targeting b-catenin signaling pathway." Toxicol Lett. 220(3): 219-228.

Kim, S. M., J. H. Lee, G. Sethi, C. Kim, S. H. Baek, D. Nam, W. S. Chung, S-H Kim, B. S. Shim, and K. S. Ahn. 2014. "Bergamottin, a natural furanocoumarin obtained from grapefruit juice induces chemosensitization and apoptosis through the inhibition of STAT3 signaling pathway in tumor cells." Cancer Lett. 354(1): 153-163.

Panno, M. L., F. Giordano, P. Rizza, M. Pellegrino, D. Zito, C. Giordano, L. Mauro, S. Catalano, S. Aquila, and D. Sisci. 2012. "Bergapten induces ER depletion in breast cancer cells through SMAD4-mediated ubiquitination." Breast Cancer Res. Treat. 136(2): 443-455.
De Amicis, F., S. Aquila, C. Morelli, C. Guido, M. Santoro, I. Perrotta, L. Mauro, F. Giordano, A. Nigro, and S. Andó. 2015. "Bergapten drives autophagy through the upregulation of PTEN expression in breast cancer cells." Mol. Cancer 14: 1 .

Ge, Z. C., X. Qu, H. F. Yu, H. M. Zhang, Z. H. Wang, Z. T. Zhang. 2016. "Antitumor and apoptotic effects of bergaptol are mediated via mitochondrial death pathway and cell cycle arrest in human breast carcinoma cells." Bangladesh J. Pharmacol. 11(2): 489-494.

Yu, J., L. Wang, R. L. Walzem, E. G. Miller, L. M. Pike, and B. S. Patil. 2005. "Antioxidant activity of citrus limonoids, flavonoids, and coumarins." J. Agric. Food. Chem. 53(6): 2009-2014.

Phuwapraisirisan, P., S. Surapinit, and S. Tip-pyang. 2006. "A novel furanocoumarin from Feroniella lucida exerts protective effect against lipid peroxidation." Phytother Res. 20: 708-710.

Navarra, M., N. Ferlazzo, S. Cirmi, E. Trapasso, P. Bramanti, G. E. Lombardo, P. L. Minciullo, G. Calapai, and S. Gangemi. 2015. "Effects of bergamot essential oil and its extractive fractions on SHSY5Y human neuroblastoma cell growth." J Pharm Pharmacol. 67(8): 1042-1053.

Hwang, Y. P., H. J. Yun, J. H. Choi, K. W. Kang, and H. G. Jeong. 2010. "Suppression of phorbol-12-myristate13-acetate-induced tumor cell invasion by bergamottin via the inhibition of protein kinase $\mathrm{Cd} / \mathrm{p} 38$ mitogen-activated protein kinase and JNK/nuclear factor-kB-dependent matrix metalloproteinase-9 expression." Mol Nutr Food Res. 54(7): 977-990.

Girennavar, B., G. Jayaprakasha, Y. Jadegoud, G. N. Gowda, and B. S. Patil. 2007. "Radical scavenging and cytochrome P450 3A4 inhibitory activity of bergaptol and geranylcoumarin from grapefruit." Bioorgan Med Chem. 15: 3684-3691.

Pan, M. H., C. S. Lai, C. T. Ho. 2010. "Anti-inflammatory activity of natural dietary flavonoids." Food Funct. 1(1): $15-31$.

Meng, F. H., Z. L. Xiong, Y. Sun, and F. Li. 2004. "Coumarins from Cnidium monnieri (L.) and their proliferation stimulating activity on osteoblast-like UMR106 cells." Pharmazie. 59: 643-645. 
Table 1. Specific health benefits per furanocoumarin.

\begin{tabular}{|c|c|c|c|}
\hline & Bergaptol & Bergapten & Bergamottin \\
\hline Breast Cancer & increase cell death & $\begin{array}{l}\text { inhibit cell growth } \\
\text { induce tumor cell death }\end{array}$ & inhibit cell signaling \\
\hline Leukemia & & & $\begin{array}{l}\text { decrease cell growth } \\
\text { decrease tumor cell numbers }\end{array}$ \\
\hline Skin cancer & & & inhibit cell growth \\
\hline Stomach cancer & & & inhibit cell growth \\
\hline Osteoporosis & & $\begin{array}{l}\text { increase cell division } \\
\text { increase cell denisty } \\
\text { increase cell development }\end{array}$ & \\
\hline Fibrosarcoma & & decrease metastasis & \\
\hline Neuroblastoma & & increase cell death & $\begin{array}{l}\text { triggers cell death } \\
\text { decrease metastasis }\end{array}$ \\
\hline Free radicals & scavenged & scavenged & \\
\hline Lipid peroxidation & delayed & delayed & \\
\hline
\end{tabular}

